\title{
REFLEXÕES ACERCA DO USO DAS METODOLOGIAS PARTICIPATIVAS APLICÁVEIS AOS CALDEIRÕES EM LAJEDO-PE NO CONTEXTO DA EDUCAÇÃO AMBIENTAL
}

Reflections on the use of methodologies applicable to caldeirões in potholes Lajedo-PE in the context of environmental education

Reflexiones acerca del uso de las metodologías participativas aplicables a los caldeirões en Lajedo-PE em el contexto de la educación ambiental

Jeovanes Lisboa da Silva Filho Graduando em Licenciatura em Geografia, UPE/Campus Garanhuns, Brasil Bolsista PIBIC/PFA 2016 jeovanelisboa@hotmail.com

Leticia Florentino dias de Oliveira Graduanda em Licenciatura em Geografia, UPE/Campus Garanhuns, Brasil Bolsista PIBIC/CNPq 2015-2016 leticia.idias@bol.com.br

Maria Betânia Moreira Amador Professora Doutora em Geografia, UPE/Campus Garanhuns, Brasil betaniaamador@yahoo.com.br 
RESUMO

A intensão de trazer à tona o método ambiental participativo no presente trabalho, partiu da necessidade de refletir sobre esse tipo de metodologia e ver a possibilidade de sua aplicação, no futuro, na área dos Caldeirões em Lajedo/PE. Outro dado importante, é a sua funcionalidade enquanto instrumento para a educação e a gestão ambiental. Logo, o caminho metodológico adotado é a busca ampla desse tipo de metodologia na literatura disponível em livros, revistas, periódicos científicos, anais de eventos, dissertações de mestrado e teses de doutorado. Assim, as leituras e sistematização dos dados, poderão apontar potenciais canais de aplicação desse método, sobretudo no que diz respeito as práticas ambientais e elaboração de diagnósticos de cunho ambiental, os quais serão resultados, também, das percepções das pessoas que residem no entorno da área que já foi alvo de pesquisas anteriores, ou seja, "Os Caldeirões". Com relação aos resultados, verificou-se até o momento que essas metodologias desenvolvidas, por exemplo, no estado de São Paulo, foram mais aplicadas em bacias hidrográficas para fins de planejamento de recursos hídricos, mas que, poderão ser aplicadas na área dos Caldeirões, mesmo se tratando de um fragmento geomorfológico. Pois, o mesmo interage com outros elementos em seu entorno, inclusive os recursos hídricos de suas cavidades, além do Riacho Doce que perpassa em suas imediações. Por fim, vale destacar o amadurecimento dessas ideias, mesmo que unicamente de ordem bibliográfica, no momento, procurando-se verificar e entender outras experiências na intenção de aplicá-las no futuro.

PALAVRAS-CHAVE: Método Participativo. Abordagem Sistêmica. Educação Ambiental.

\section{ABSTRACT}

The intension of bringing out the participatory environmental method in this work stemmed from the need to reflect on this type of methodology and view the possibility of its application in the future in the area of Potholes in Lajedo-PE. Another important, is its functionality as a tool for education and environmental management. Thus, the adopted methodological approach is the broad search of this type of methodology in the literature available in books, magazines, journals, conference proceedings, dissertations and doctoral theses. Thus, readings and systematization of data, may indicate potential application channels of this method, especially regarding environmental practices and development of environment-related diagnoses, which will be results, also, the perceptions of the people residing in the vicinity of area that has been the subject of previous studies, namely "potholes." Regarding the results, it has been found to date that these methodologies developed, for example in the state of São Paulo, were more applied in watersheds for planning purposes of water resources, but may be applied in the area of cauldrons, even when they are dealing with a geomorphological fragment. For it interacts with other elements in your environment, including water resources in their cavities, besides the Sweet Creek that runs through in their vicinity. Finally, it is worth highlighting the maturity of these ideas, even if only bibliographic order at the time, seeking to verify and understand other experiences in an attempt to apply them in the future.

KEYWORDS: Participatory Method. Systemic Approach. Environmental Education.

\section{RESUMEN}

La intención de traer a la luz el método ambiental participativo en el presente trabajo partió de la necesidad de reflejar acerca de ese tipo de metodología y ver la posibilidad de su aplicación, en el futuro, en el área de los Caldeirões en Lajedo/PE. Otro dato importante, es su funcionalidad mientras instrumento para la educación e la gestión ambiental. Luego, el camino metodológico adoptado es la busqueda amplia de ese tipo de metodología en la literatura disponible en libros, revistas, periódicos científicos, anales de eventos, disertaciones de maestria y tesis de doctorado. Así, las lecturas y sistematización de los datos, podrán apuntar potenciales canales de aplicación de ese método, sobre todo en lo que se refiere a las prácticas ambientales y elaboración de diagnósticos de carácter ambiental, los quales serán resultados, también, de las percepciones de las personas que viven en el entorno del área que ya fue objeto de pesquisas anteriores, o sea, "Os Caldeirões". Con relación a los resultados, se ha verificado hasta el momento que esas metodologias desarrolladas, por ejemplo, en el estado de São Paulo, fueron más aplicadas en cuencas hidrográficas con fines de planeamiento de recursos hídricos, pero que, podrán ser aplicadas en el área de los Caldeirões, mismo tratandose de un fragmento geomorfológico. Pues, lo mismo está en contacto con otros elementos en su entorno, incluso los recursos hídricos de sus cavidades, además del Riacho Doce que pasa por sus imediaciones. Por fin, vale destacar la maduración de esas ideas, mismo que solamente de orden bibliográfica, en el momento, buscandose verificar y comprender otras experiencias con intención de aplicarlas en el futuro.

PALABRAS-CLAVE: Método Participativo. Enfoque Sistemico. Educación Ambiental. 


\title{
1 INTRODUÇÃO
}

\begin{abstract}
Afinal, de que serviriam todos os saberes senão para formar uma configuração que responda a nossas expectativas, nossos desejos, nossas interrogações cognitivas? (MORIN, 2003, p. 108).
\end{abstract}

Os objetivos para a realização do trabalho que se apresenta, se constituem em analisar sob o ponto de vista da abordagem sistêmica, a possibilidade de aplicação da metodologia participativa, inclusive seus mapeamentos, na bibliografia contemporânea disponível com vistas a que possam ser usadas no futuro, para identificar potenciais caminhos de aplicação de estudo, pesquisa, gestão e práticas ambientais na área dos Caldeirões em Lajedo-PE.

Os Caldeirões e/ou Marmitas são um conjunto de lajedos responsáveis pelo surgimento dos primeiros assentamentos do lugar, hoje cidade de Lajedo-PE. Esses conjuntos de rochas estão inseridas na área central da cidade, e apresentam um grande valor histórico e cultural. No tempo presente, os Caldeirões não são devidamente preservados, tendo em vista vários fatores, entre os quais pode-se citar a proliferação de esgotos, construções irregulares, animais soltos na área, deposito inadequado de resíduos sólidos, entre outros.

Para a realização dessa pesquisa, optou-se pela abordagem sistêmica, mas tentando buscar informações mais contundentes através do uso do método participativo, o que inclui o processo de mapeamento dessa participação, e quais as suas contribuições para a gestão e educação ambiental aplicável aos Caldeirões.

Assim, pode-se associar interdisciplinarmente e trandisciplinarmente elementos do sistemismo e de participação direta da comunidade local integrando aspectos do ambiente, o que inclui os geológicos-geomorfológicos, biogeográficos, a categoria de análise lugar e outros, ao mesmo tempo em que oportuniza pensar e/ou refletir sobre a percepção das pessoas, em geral, em relação a sustentabilidade ambiental, especialmente quando se toma o "lugar" como categoria de análise.

Logo, julga-se importante o método participativo e seus mapeamentos que, nesse contexto visa realmente, valorizar o conhecimento comum na perspectiva de agregar este ao conhecimento científico.

De acordo com Dagnino (2007), o método participativo remete à relevância de utilizar cientificamente, via análise qualitativa, a percepção e o conhecimento da população envolvida cotidianamente com os riscos ambientais. E busca, ainda, fornecer subsídios para que as comunidades afetadas obtenham maior eficácia na argumentação e no encaminhamento de melhorias, de medidas corretivas e de soluções estruturais.

Assim sendo, a proposta que se apresenta visa, fundamentalmente, encontrar, estudar e articular várias facetas inerentes aos trabalhos participativos que possam ser aplicados em algum ponto do futuro para contribuir na sustentabilidade dos Caldeirões de Lajedo/PE sob, também, o ponto de vista da Topofilia que expressa o afeto pelo lugar (TUAN, 2012).

$\mathrm{O}$ artigo segue a sua estrutura fazendo uma breve caracterização do município de Lajedo e da área dos Caldeirões e, logo após tese considerações acerca das metodologias participativas e a 
educação ambiental numa perspectiva sistêmica. $E$, ressalta também como se procede a metodologia adotada no trabalho, finalizando com as considerações finais.

\section{OS CALDEIRÕES E O MUNICÍPIO DE LAJEDO-PE}

O município de Lajedo-PE encontra-se inserido na Província do Planalto da Borborema e, apresenta um relevo levemente ondulado situado na Microrregião de Garanhuns (Figura 1). Devido a sua localização ser em uma área de transição entre o Sertão e a Zona da Mata, o seu bioma apresenta ora características de Caatinga, ora Mata Atlântica, bem como um clima que varia entre o sub úmido ao semiárido.

De acordo Instituto Brasileiro de Geografia e Estatística (IBGE, 2015), o município já citado dispõe de aproximadamente 39.240 habitantes, e sua área total é de $189.096 \mathrm{Km}^{2}$.

Figura 1: Localização do Município de Lajedo-PE

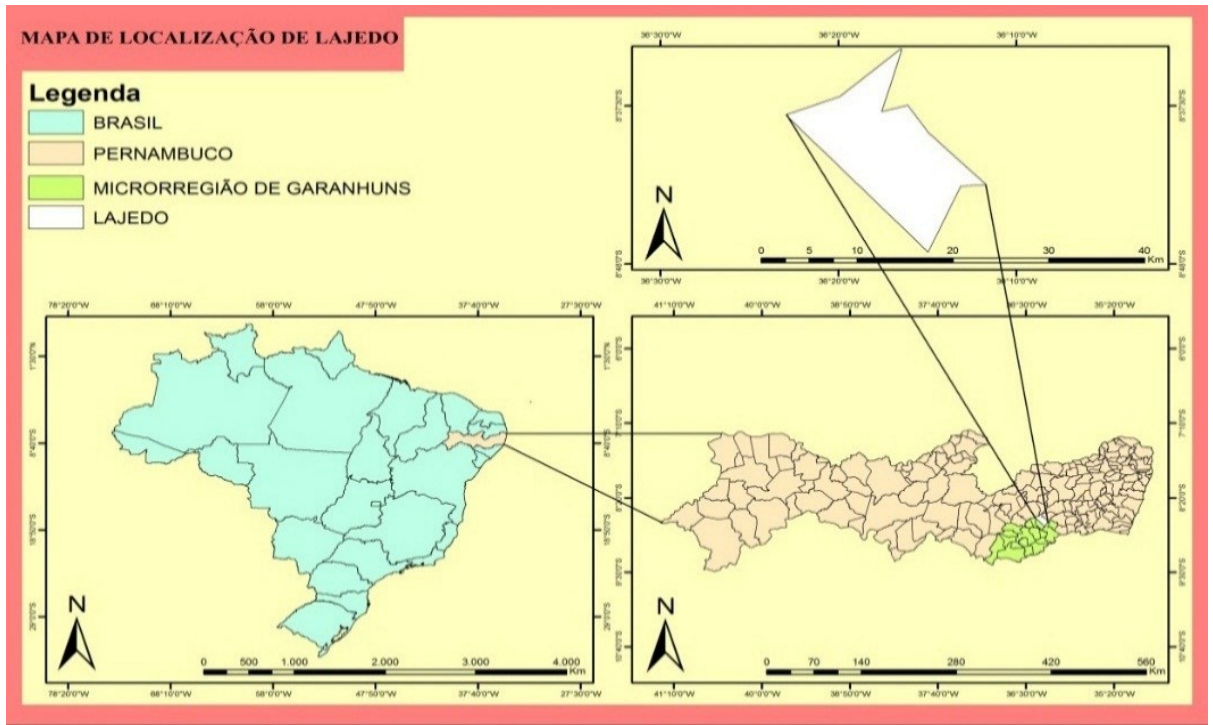

Fonte: RENILSON RAMOS JEOVANES LISBOA, 2014

Os Caldeirões, por sua vez, sobressaem-se na área urbana de Lajedo, especificamente no centro da cidade (Figura 2), como um elemento marcante na paisagem de ordem geológicogeomorfológica. Com base em Silva (1995, p. 25), os “Caldeirões são uma formação natural de pedra, cheia de cavidades grandes e pequenas que retinham a água da Chuva e abasteciam a população durante a estação chuvosa e intermediária".

Ainda sobre os Caldeirões, Amador e Silva Filho (2014, p. 90), destacam que "O nome do município de Lajedo/PE é oriundo desses reservatórios naturais de água, que atraiu os primeiros habitantes para onde hoje é a cidade".

Essa formação rochosa conta com uma área de, aproximadamente, 1.3 hectares referentes à rocha principal situada em propriedade da prefeitura municipal. Outra área, no entanto, apresenta, aproximadamente 1.8 hectares localizando-se em propriedade pública, mas de outra ordem ainda não totalmente definida se federal, estadual ou municipal. E, existe, também, uma área maior estimada em 10 hectares situada em propriedade privada, cuja principal atividade econômica é a produção de gado leiteiro. 


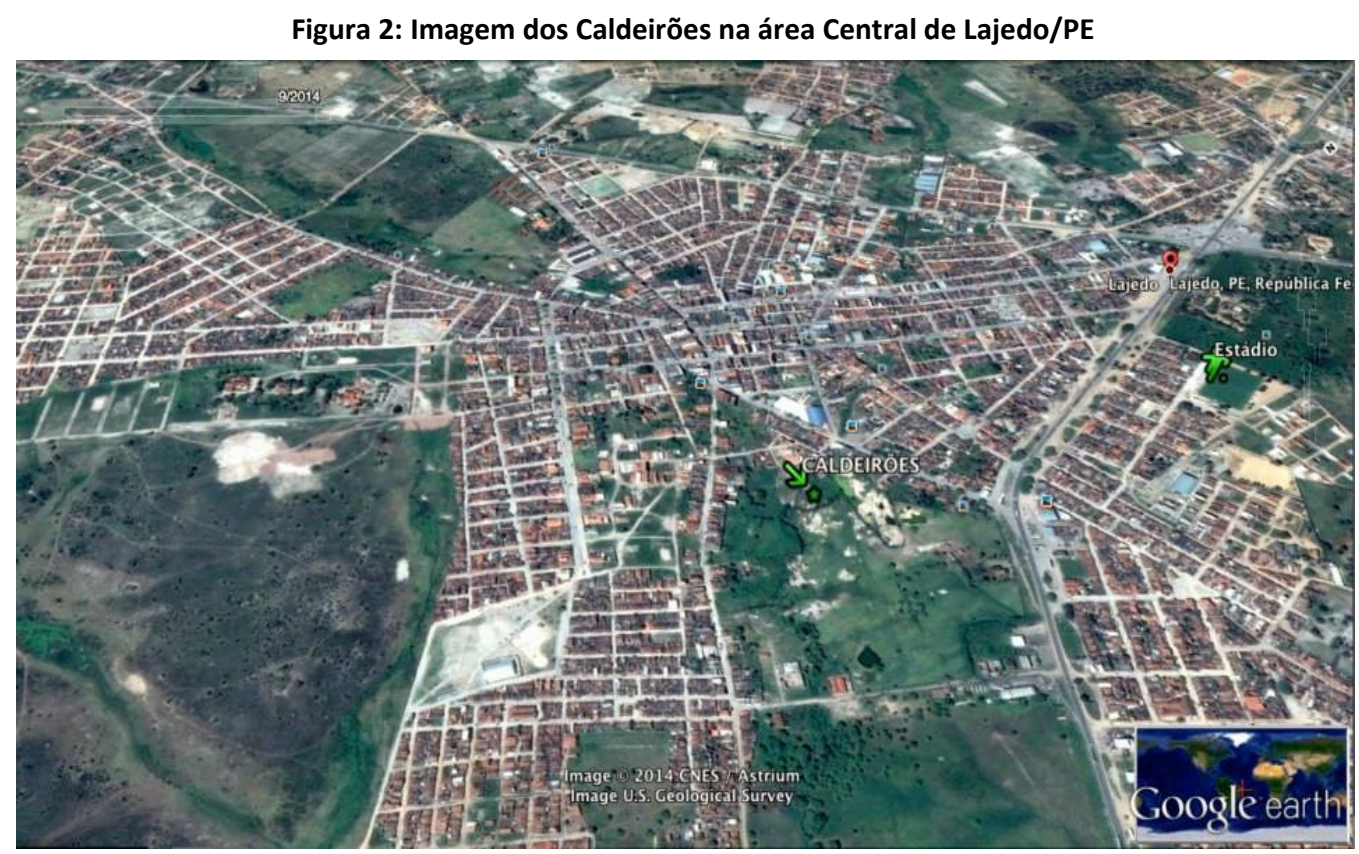

Fonte: Ong. Curta os Caldeirões, 2015

Observa-se na (Figura 02), a área dos Caldeirões inserida no centro da cidade, como bem já foi mencionado anteriormente, onde fica evidenciado o processo de urbanização, devido as diversas edificações civis ao seu entorno, sobretudo a comunidade dos Caldeirões.

Os Caldeirões, então, foram fundamentais para o processo de ocupação do lugar que originou a cidade, como também foram fundamentais no abastecimento de água, para as mais diversas utilidades, tais como: lavar roupa, tomar banho, pescar, fazer piquenique, cozinhar, entre outras para as famílias que residiam em suas imediações.

A área dos Caldeirões de Lajedo é catalogada pelo Plano de Preservação dos Sítios Históricos do Interior (PPSHI), desde 1982 e o Plano Diretor Municipal (2003), a classifica como área de proteção ambiental (APA), com lei específica para assegurar sua preservação e conservação desse local.

\section{MAPEAMENTO AMBIENTAL PARTICIPATIVO E EDUCAÇÃo AMBIENTAL NUMA PARESPECTIVA SISTÊMICA}

Não se trata de substituir binariamente essa forma de produzir ciência por outra, "mais moderna", ou "menos tecnicista". O que se pretende é adicionar e integrar as percepções, os mapas mentais e a memória coletiva junto aos métodos já amplamente utilizados nas pesquisas geográficas e ambientais (CARPI JÚNIOR; PEREZ FILHO, 2003, p. 25).

O método de mapeamento ambiental participativo que será apresentado nesse trabalho, vem sendo desenvolvido em vários municípios no estado de São Paulo desde a década de 1990, principalmente em estudos de bacias hidrográficas para fins de planejamento de recursos hídricos, inicialmente protagonizado por (SEVÁ FILHO, 1997), na região de Campinas. Logo 
após destaca-se o trabalho de (CARPI JR. 2001), na bacia hidrográfica do rio Mogi-Guaçu e (CARPI JR \& PEREZ FILHO, 2005), na bacia hidrográfica do Ribeirão das Anhumas, entre outros. O mapeamento participativo visa, fundamentalmente, a valorização daqueles que residem nas comunidades a serem estudas, bem como seus mapas mentais, os quais irão resultar em mapas participativos, onde contém as informações destacadas pela comunidade participante, a qual tem a oportunidade de destacar os problemas e/ou potencialidade de ordem ambiental e, também vulnerabilidades de ordem social do lugar que residem.

Vale ressaltar que o mapeamento ambiental participativo é um excelente instrumento para a educação e a gestão ambiental, uma vez que a primazia da troca de saberes técnicos, científicos e populares, fornecem subsídios para elaboração de diagnósticos que visam a solução de problemas em áreas de riscos, em especial os ambientais. Assim, valoriza os conhecimentos de quem reside no local que se deseja estudar, pois quem é do lugar, consegue visualizar uma gama de elementos devido as suas experiências e vivências cotidianas.

Nesse sentido, a trocas de saberes dos conhecimentos advindos das experiências cotidianas são de suma importância para a solução de problemas ambientais, e, também, funcionam como um excelente instrumento para a Educação Ambiental, o que nos remete às ideias de (AMADOR; SOARES 2014, p. 119), onde ambas destacam que "na perspectiva de atender aos princípios que ancoram a Educação Ambiental, estes são baseados na igualdade, no respeito, na ética, na cooperação e na interação da sociedade entre se e com o meio natural, tanto em escala local, como em relação ao globo".

Esse ponto de vista de Amador e Soares está totalmente associado ao que é realizado nas metodologias participativas, pois, de fato, o respeito pelo saber do outro no contexto da participação é fundamental. Ainda, referindo-se ao mapeamento participativo, a sua intenção na perspectiva de Dagnino (2007), é se basear na percepção da comunidade e seu conhecimento cotidiano para que se possa fazer uma análise científica qualitativa, a fim de apresentar o leque de informações obtidas e assim favorecer e levantar melhorias necessárias além de perpetuar e ressaltar as potencialidades e qualidades locais.

Ressalta-se também que o mapeamento participativo, antes de sua efetiva realização que ocorre durante as reuniões públicas, é precedido por confecção de material cartográfico base, no qual será "desenhado ou escrito" as áreas de riscos ambientais, para que se tenha o conhecimento da área a ser estudada, como também, no que se que refere a escolha do local onde serão realizadas as reuniões públicas de caráter participativo com a população. Por isso, faz-se necessário fazer parcerias, muitas vezes com secretarias municipais, seja de educação, meio ambiente, agricultura, associações, entre outros que por ventura forem necessários, a depender do interesse e objetivos do trabalho.

É importante ressaltar que para boa adaptabilidade desse método, quanto mais participantes melhor. Assim que é definido o local e data das reuniões, bem como a elaboração do material cartográfico com as legendas que serão utilizadas, já pode ser enviado os convites e cartas para as diversas pessoas da sociedade. Na parte inicial da reunião de mapeamento de riscos ambientais, explica-se detalhadamente a importância do estudo, o quão é essencial a participação da população nessa etapa, uma vez que é uma das mais importantes e decisiva.

Os participantes são divididos em grupos de trabalho, onde fica um mediador em cada um deles, bem como outra pessoa para fazer anotações do que está sendo expressado pelas pessoas. Ressalta-se também, a importância de comunicar aos participantes os objetivos do trabalho e a contribuição de sua participação. Feito isso, inicia-se o processo de alfabetização cartográfica e/ou geocartográfica baseada em Sevá Filho e Carpi Junior, onde é incentivado a habilidade dos participantes em observar o mapa que lhes é apresentado e correlacionar lugares, objetos, ou seja, pontos de referência que remetam a sua percepção da realidade 
através de mapas mentais que cada um deles possui do lugar, o qual pertencem, e/ou convivem diariamente.

A legenda que é apresentada, geralmente dispõe de cinco eixos principais para caracterização de riscos ambientais, são eles: água, ar, solo, resíduos e vulnerabilidade social (Figura 3), os quais podem ser adaptados de acordo com à criatividade e melhor entendimento daqueles que ali estão. Assim, pode-se, de fato, dar-se início a efetiva reunião pública para mapeamento participativo de riscos ambientais.

Figura 3: Legenda base utilizada nas reuniões de mapeamento

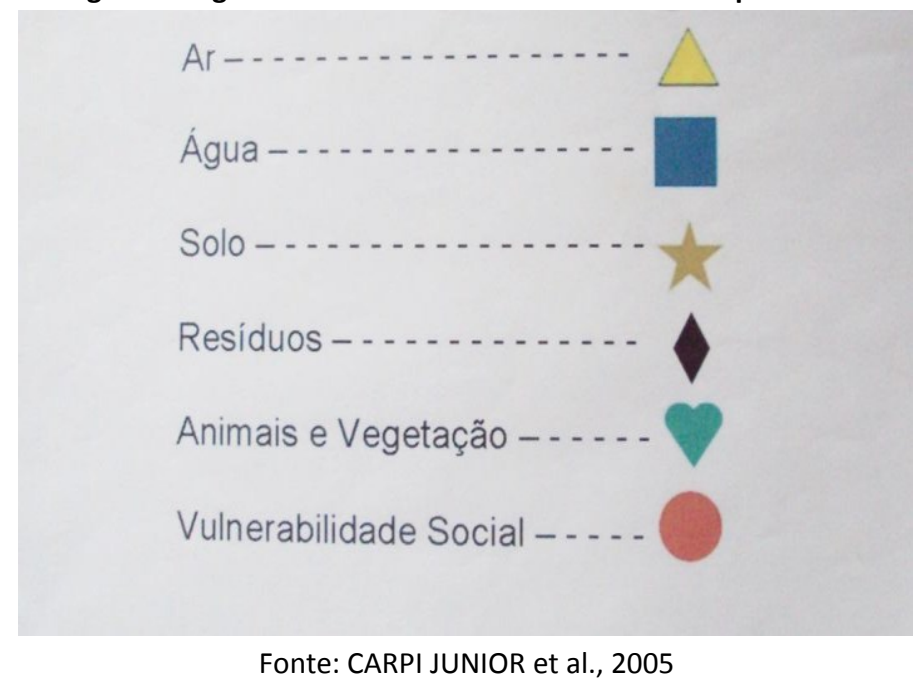

Em consonância com o que já foi abordado no presente método, verifica-se salutar a experiência de pensar no planejamento, e na sustentabilidade a partir do disposto em referencias que tratam do uso de métodos participativos e seus mapeamentos, os quais poderão, em sua generalidade, indicar formas, atitudes e procedimentos técnicos coadunados com a ideia de percepção aplicada ao lugar como se capta nas leituras de Yi Fu Tuan (2012), associadas, também, com a afetividade do proponente da pesquisa, oriundo do lugar que esteja sendo estudado.

Então, é nesse momento que emerge a importância da abordagem sistêmica para trabalhar todos os fenômenos captados nas percepções em contexto e de maneira interdisciplinar, fazendo a interconexão dos diversos elementos existentes na troca de saberes, tendo em vista que estes coadunam com a ideia de complexidade, entendendo-se por complexidade sob a concepção miriniana.

A complexidade, por sua vez, é aplicada na Geografia por meio da abordagem sistêmica, pois como bem ressalta Vasconcelos (2015), o cientista novo-paradigmático que opta por trabalhar sistemicamente, é preciso pensar a complexidade, instabilidade e a intersubjetividade. A abordagem sistêmica com base em Amador, visa:

Pensar e agir, em qualquer área de estudo e refletir os problemas sob o aspecto da ordem, da organização, da totalidade, entre outros. Logo, são abordagens que fogem ao tradicional reducionismo da ciência que, busca entender os fenômenos, prioritariamente, pelo observável e pelo testável, vindo a contribuir ao longo do tempo na extrema especialidade que esquece, ou não encontra espaço para entender o todo, ficando retido, apenas, na questão da causa e efeito de forma linear (AMADOR, 2006 pág. 26). 
Como destacado por Amador, e com base nos referenciais pertinentes as metodologias participativas, percebe-se o quanto a abordagem sistêmica ela pode ser um fundamento balizador para se trabalhar envolvendo a troca de saberes, pois ela permite estudar, refletir e analisar as percepções das pessoas no sentido amplo, lembrando que, é também aplicada a Educação Ambiental e suas respectivas práticas.

\section{PROCEDIMENTOS METODOLÓGICOS}

O método adotado para desenvolver a presente pesquisa é a abordagem sistêmica, a qual com base em (DEMO, 2012), esconde atrás de si certa decepção com o especialista que sabe a idiotice tudo sobre penas certa coisa, ou seja, o profissional que se arvora pela rota sistêmica, procura fazer uma análise integrada a abrangente do seu objeto de pesquisa.

Logo, essa perspectiva sistêmica vai permitir que o autor possa buscar informações mais contundentes sobre as metodologias participativas em bibliotecas, periódicos científicos, anais de eventos, livros, dissertações de mestrado, teses de doutorado, entre outros, para que, possam subsidiar em reflexões e na possibilidade futura de se trabalhar com as metodologias pensando em sua aplicabilidade, no contexto da educação e as práticas ambientais na comunidade dos Caldeirões em Lajedo/PE.

Assim, oportuniza pensar e/ou refletir sobre a percepção das pessoas, em geral, em relação a sustentabilidade ambiental, especialmente quando se toma o "lugar" como categoria de análise. Logo, isso implica em uma gama de leituras e sistematização de dados, uma vez que essa pesquisa, inicialmente, é de caráter qualitativa e exploratória. Contudo, considera-se pertinente chamar atenção para o que destaca Suertegaray (2005), onde ela enfatiza que devemos recorrer ao sistemismo no âmbito da Geografia, não como uma teoria interpretativa, mas um caminho analítico, um método.

\section{RESULTADOS PRELIMINARES}

Com relação aos resultados obtidos nas leituras realizadas, contatou-se que as metodologias de cunho participativo na maioria dos casos foram aplicadas em bacias hidrográficas, mas isso não significa dizer que elas não sejam aplicadas a outras realidades, como foi o caso do trabalho de Silva (2016), o qual foi trabalhado na zona rural do município de São José do Rio Pardo, SP.

Verificou-se também, que essas metodologias são de suma importância enquanto instrumento para a Gestão e a Educação Ambiental, e que nas reuniões públicas de caráter participativo, é possível que haja uma participação ativa de todos, não importa o ou grau de instrução, tanto pode ser um doutor, ou até mesmo um trabalhador braçal, até quem é analfabeto tem a oportunidade de participar, pois mesmo não sabendo ler, ele tem a oportunidade de apontar os seus anseios através das cores disponíveis na legenda base, e, na verdade, a ideia de fato é a valorização dos mapas mentais dos participantes.

Outro detalhe importante, é que essas metodologias, mesmo sabendo que a maioria de suas aplicações foram em bacias hidrográficas para fins de planejamento e gerenciamento de 
recursos hídricos, podem ser aplicadas na área dos Caldeirões, mesmo se tratando de um componente geomorfológico, mas sabe-se que ele está inserido na área central de uma cidade, interagindo com outros elementos em seu entorno, inclusive os recursos hídricos de suas cavidades, além do Riacho Doce que perpassa em suas imediações, vegetação, animais, entre outros.

Além do que, encontra-se com diversos impactos de ordem ambiental, podendo, nesse caso, haver esforços e troca de saberes entre todos, envolvendo setor público, privado, comunidade, associações e universidades, para juntos decidirem, articularem e proporem os eventuais caminhos e estratégias pensando no planejamento e Gestão dessa área, e também em Educação Ambiental para a população, sobretudo os mais jovens que apresentam pouca e/ou quase nenhuma afeição pelos Caldeirões, como já se constatou em estudos anteriores de Silva Filho e Amador (2015).

\section{CONSIDERAÇÕES FINAIS}

Esse trabalho, de certa forma, contribui com reflexões acerca das metodologias participativas disponíveis nos referenciais disponíveis por pesquisadores bem instruídos a respeito do assunto, os quais também ressaltam o quanto essas metodologias são de suma importância quando aplicadas no contexto da gestão e a educação ambiental, e suas respectivas práticas.

Importa destacar que as maiores experiências realizadas com o mapeamento ambiental participativo tenham sido com bacias hidrográficas e planejamento de recursos hídricos, no entanto, vale salientar a possibilidade de aplicação dessa metodologia na área dos Caldeirões em Lajedo-PE, a qual poderá subsidiar em um planejamento e diagnostico de cunho ambiental para tal localidade, incluindo, é claro, a Educação Ambiental para a comunidade que reside no entorno.

A pesquisa está em fase inicial de realização e é unicamente de ordem bibliográfica, com o intuito de amadurecimento de ideais, as quais poderão apontar caminhos de aplicação dessa metodologia, no futuro, na área dos Caldeirões através de um trabalho posterior que se pretende realizar.

Considera-se relevante mencionar, a abordagem sistêmica enquanto opção teóricometodológica, uma vez que o sistemismo oportuniza realizar o estudo de maneira integrada, que no caso aqui em pauta, trata-se de uma busca ampla nas literaturas referentes as metodologias participativas, bem como a sua funcionalidade para se trabalhar com a educação ambiental.

Por fim, espera-se que, de fato, essas metodologias possam enfim serem aplicadas, no futuro, de preferência em conjunto com a universidade, comunidade, setor público, privado, associações, onde todos juntos possam apontar os problemas de ordem ambiental e vulnerabilidades social, como também os possíveis potenciais da área dos Caldeirões e, sugerir soluções no contexto da educação e gestão ambiental no sentido de haver, inclusive, uma melhor qualidade de vida para os que residem no entorno dessa área com o quesito ética norteando a condução dos trabalhos. 


\section{REFERÊNCIAS}

AMADOR, Maria Betânia Moreira. Sistemismo e sustentabilidade: questão interdisciplinar. São Paulo: Scortecci, 2011.

. "Topofilia" aplicado ao estudo de componentes geomorfológicos considerados patrimônios no Agreste de Pernambuco. Revista Equador. V 04, no 03, ano 2015. Edição especial 02. p. 171-177, 2015.

O sistêmico e as questões teórico-metodológicas da sustentabilidade no âmbito da geografia. II Fórum Ambiental da Alta Paulista. Tupã, SP: ANAP/FACCAT/UNESP, 2006. 1 CDRom sob o ISSN 1980-0827. Disponível em: <http://www.amigosdanatureza.org.br/notícias/306/trabalhos/115. AS-8.pdf>. Acesso em: 30 março 2015.

AMADOR, Maria Betânia Moreira; SOARES, Maria José Nascimento. Troca de saberes: percepções desiguais em relação ao apoderar-se de ideias em Educação Ambiental. In SILVA, G.M; JUNA, J.; SOARES, M.J.N. Diálogos teóricos e práticos com a pesquisa. São Paulo, Vila Rica, pp.117-126, 2014.

CARPI JÚNIOR, Salvador; PEREZ FILHO, Archimedes. Participação popular no mapeamento de riscos ambientais em bacias hidrográficas. Anais do X Simpósio Brasileiro de Geografia Física Aplicada, Rio de janeiro, nov. 2003.

Riscos ambientais na Bacia do Rio Mogi-Guaçu: proposta metodológica. Geografia, Rio Claro, v. 30, n. 2, p. 347-364, 2005.

CARPI JÚNIOR, Salvador. Processos erosivos, riscos ambientais e recursos hídricos na Bacia do Rio Mogi-Guaçu. Tese de Doutorado em Geociências e Meio Ambiente. Rio Claro: IGCE/UNESP, 2001. 188 p. Orientações: Prof. Archimedes Perez Filho.

DAGNINO, Ricardo de Sampaio. Riscos ambientais na bacia hidrográfica do Ribeirão das Pedras. Dissertação de Mestrado em Geografia. IG/UNICAMP, 2007. 127 p. Orientações: Prof. Dr. Francisco Sérgio Bernardes Ladeira.

; CARPI JUNIOR. História, Desafios e Perspectivas do Mapeamento Ambiental Participativo no Estado de São Paulo, In: DIAS, L.S.: BENINI, S. Estudos Ambientais Aplicados em Bacias Hidrográficas. Tupã, ANAP, pp. 13-28, 2014.

DEMO, Pedro. Metodologia Científica em ciências sociais. 3 ed. São Paulo: Atlas, 2012.

GUERRA, Antônio José Teixeira; CUNHA, Sandra Baptista da (Orgs.). Geomorfologia: uma atualização de bases e conceitos. 10 ed. Rio de Janeiro: Bertrand Brasil, 2011.

IBGE. Instituto Brasileiro de Geografia e Estatística. 2015 Disponível em: $<$ http://www.censo2010.ibge.gov.br/sinopse/index.php?uf=26\&dados=26>. Acessado em Janeiro de 2015. 
MORALES, Angélica Góes. A formação do profissional educador ambiental: reflexões, possibilidades e constatações. Ponta Grossa: Ed. UEPG, p. 203, 2009.

MORIN, Edgar. Introdução ao Pensamento Complexo. 5 ed. Tradução de Eliane Lisboa. Porto Alegre: Sulina, 2015.

A cabeça bem feita: repensar a reforma, reforçar o pensamento. Rio de Janeiro: Bertrand Brasil, 2004.

SEVÁ FILHO, A. O. e CARPI JUNIOR, S. Síntese das atividades e resultados dos projetos Riscos Ambientais na Bacia do Rio Mogi-Guaçu. 25 p, 2002. Disponível em: <http://www.researchgate.net/profile/Ricardo_Dagnino/publication/233381856_Mapeament o_participativo_de_riscos_ambientais_na_Bacia_Hidrogrfica_do_Ribeiro_das_Anhumas__Campinas_SP/links/Ofcfd50b749078f87b000000.pdf>. Acesso em: 25 de janeiro de 2015.

SILVA, Amanda Cristina Alves. Mapeamento Participativo de Riscos ambientais no bairro rural Água Fria, São José do Rio Pardo. 2015. 67 p. Monografia (Bacharelado em Geografia) Universidade Estadual de Campinas, Instituto de Geociências. Campinas, 2015.

SILVA, Antônio de Oliveira e. Lembranças da primavera: Memórias. Lajedo: Edição do autor, 1995.

SILVA FILHO, Jeovanes Lisboa; AMADOR, Maria Betânia Moreira. A Paisagem Geomorfológica dos Caldeirões em Lajedo-PE sob uma Visão Sistêmica do Ambiente. In: Periódico Eletrônico do X Fórum Ambiental da Alta Paulista. Patrimônio Histórico, Turismo e Desenvolvimento Local. v. 10 p. 92-97. ISSN 1980-0827 Disponível em:

<http://www.amigosdanatureza.org.br/publicacoes/index.php/forum_ambiental/article/view/ 795/819> Acesso em: 10 de Fevereiro de 2015.

A visão sistêmica contribuindo para o estudo da paisagem geomorfológica dos caldeirões em Lajedo-PE. XVI Simpósio Brasileiro de Geografia Física Aplicada. Teresina/PI Junho/Julho, 2015.

SUERTEGARAY, Dirce Maria Antunes. O atual e as tendências do ensino e da pesquisa em geografia no Brasil: Revista do Departamento de Geografia, n. 16, p. 38 - 45, 2005. Disponível em: <http://www.geografia.fflch.br/publicacoes/RDG/RDG 16/Dirce Maria Antunes Suertegaray.pdf>. Acesso em: 15 Jan. 2015.

TUAN, Yi - Fu. Topofilia: um estudo da percepção, atitudes e valores do meio ambiente. Tradução de Lívia de Oliveira. Londrina, PR: Eduel, 2012.

Eduel, 2013.

Espaço e lugar: a perspectiva da experiência. Tradução de Lívia de Oliveira. Londrina:

VASCONCELLOS, Maria José Esteves de. Pensamento sistêmico: o novo paradigma da ciência. 10 ed. Campinas, São Paulo: Papirus, 2015. 